\title{
THE CREDIBILITY OF CENTRAL BANK ANNOUNCEMENTS
}

Marco Hoeberichts

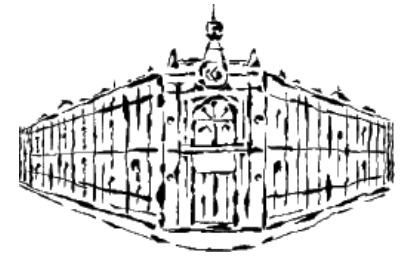

Banco de España - Servicio de Estudios

Documento de Trabajo n. ${ }^{\circ} 0221$ 


\title{
The Credibility of Central Bank Announcements
}

\author{
August 2002* \\ Marco Hoeberichts \\ Center for Financial Studies \\ Taunusanlange 6, 60329 Frankfurt am Main, Germany \\ hoeberichts@ifk-cfs.de
}

\footnotetext{
* A previous version of this paper was written while the author was visiting research fellow at the Bank of Spain. The Research Department of the Bank of Spain is gratefully acknowledged for its support and hospitality. Helpful comments were made by seminar participants at the Bank of Spain, European Central Bank, Deutsche Bundesbank, Tilburg University and University of Frankfurt. All remaining errors are mine.
} 


\begin{abstract}
In this paper, we present a monetary policy game in which the central bank has a private forecast of supply and demand shocks. The public needs to form its inflationary expectations and can make use of central bank announcements. However, because of the credibility problem that the central bank faces, the public will not believe a precise announcement. By extending the arrangement proposed by Garfinkel and Oh (1995) to a model that includes private information about both demand and supply shocks, we investigate the feasibility of making imprecise credible announcements concerning the rate of inflation.
\end{abstract}

Keywords: monetary policy, private information, announcements

JEL codes: E52, E58 


\section{Introduction}

Central banks gather a lot of information about real and nominal variables in the economy. Much of this information is publicly available, but some of it is private information. Recently, several papers have provided indications that central bank's produce better forecasts of inflation than private-sector forecasters (see, e.g. Romer and Romer, 2000 and Peek, Rosengreen and Tootell, 1999). In this paper, we assume that the monetary authority has private information about aggregate demand and supply shocks and we investigate the incentives and possibilities of the central bank regarding the communication of this private information to the public. We use a simple model with aggregate demand and aggregate supply, where monetary policy aims to stabilize the rate of inflation around a target (normalized at zero) and output around an ambitious target that is higher than the natural rate. The central bank can perfectly control the nominal interest rate. Through the nominal interest rate it can influence the real interest rate (in the short run, when inflationary expectations are fixed) and aggregate demand. The central bank has an imperfect private forecast about aggregate demand and supply shocks. The first-best policy is for the central bank to realize that it cannot consistently push output above its natural level and to commit itself to setting an average nominal interest rate equal to zero, only allowing for deviations in order to stabilize aggregate demand and supply shocks. Monetary policy is aiming for a zero rate of inflation and the public expects this rate to materialize. However, since the central bank has an ambitious output objective, it has an incentive to cheat and set the nominal interest rate lower in order to stimulate output. The central bank stimulates aggregate demand, pushes up the output gap and thereby creates a higher rate of inflation. Of course, the public recognizes this incentive and expects the monetary authority to create some inflation. In equilibrium, the central bank cannot fool the public systematically.

This outcome is inefficient: It suffers from an inflationary bias, which means that average inflation is too high, fully anticipated and hence without any effect on output. To get rid of this inefficiency, we need to bind the hands of the central bank. We could subject it to an interest rate rule. Ideally, we would want to implement the first-best solution by having the nominal interest rate equal to the long-term neutral real rate, allowing for stabilization based on the forecast of supply and demand shocks. However, the private forecast cannot be checked and it has an incentive to distort its forecast. In this respect, this papers differs from Geraats (2001) and Yetman (2002) who study the desirability of publishing central-bank forecasts under the assumption that a central bank announcement is always credible. 
The monetary authority cannot make credible announcements that give precise information about its private forecast of a shock to aggregate demand or supply.

The problem is that the monetary policy maker has one instrument and two (incompatible) goals. Therefore, it has an incentive to cheat and since it incurs no cost if it lies about its forecast, its announcements will not be believed. Precise announcements are "cheap talk" in the sense that providing the information costs nothing and providing false information does not bring costs either.

In a different model, Garfinkel and Oh (1995) apply Crawford and Sobel's (1982) analysis of strategic information transmission to show that the central bank can credibly announce a range for private forecasts of money demand shocks. Stein (1989) uses the same methodology in a model with private information regarding the exchange rate target. In this paper, we show under which conditions the central bank can announce a range in which its forecast of inflation falls. The cut-off point can be chosen in such a way that lying about private information becomes too costly, which enables the monetary authority to communicate truthfully but imprecisely its private information to the public.

The outline of the paper is as follows. First, we present a simple model of aggregate supply and demand and the monetary authority's objective function. Then, we evaluate several monetary policy regimes without announcements. Since precise announcements are not credible, we analyze imprecise announcements of expected inflation. Finally, we introduce interest rate announcements on top of inflation announcements. By comparing the outcomes of the regimes, we will look at feasibility and desirability of the announcements. The last section concludes.

\section{Model}

The central bank's monetary policy instrument is the nominal interest rate $i_{t}$. The nominal interest rate influences the real interest rate which affects the output gap.

$$
y_{t}-\bar{y}=-b\left(i_{t}-\pi_{t}^{e}\right)+v_{t}
$$

Aggregate supply is determined by a standard Lucas supply curve. Surprise inflation pushes output higher than the natural level. 


$$
y_{t}=\bar{y}+\theta\left(\pi_{t}-\pi_{t}^{e}\right)+e_{t}
$$

where $\pi_{t}$ the rate of inflation, $e_{t}$ indicates an aggregate supply shock, $v_{t}$ an aggregate demand shock, $\pi_{t}^{e}$ represents the public's inflationary expectations and $\theta$ measures the effect of inflation surprises on the level of output. Aggregate supply is allowed to deviate from its natural level if the rate of inflation exceeds inflationary expectations.

In equilibrium, the rate of inflation, for given inflationary expectations and nominal interest rate, equals:

$$
\pi_{t}=\pi_{t}^{e}-\frac{b\left(i_{t}-\pi_{t}^{e}\right)}{\theta}+\frac{v_{t}-e_{t}}{\theta}
$$

The central bank's objective is to stabilize output and inflation around its target values.

Without loss of generality, we fix the target level of inflation and the natural level of output at zero.

$$
U_{t}^{C B}=-\left(y_{t}-y^{*}\right)^{2}-f \pi_{t}^{2}
$$

where $f>0$ indicates the weight the central bank attaches to inflation stabilization relative to output stabilization. Furthermore, we assume that the central bank has an ambitious output target. That is, the central banks desired rate of output growth $y^{*}$ is larger than the natural level of output.

The central bank has a private forecast of both the supply and the demand shock. This is not a perfect forecast, but the variance of the central bank's forecast error is smaller than the variance of the public's forecast error. For the further analysis, we assume that the public just knows the distribution of the shocks and we disregard the central bank's forecast error. In the linear-quadratic framework that we present here, certainty equivalence holds and therefore both the central bank and the public can act as if the central bank's forecast were perfect. Conceptually, however, the presence of forecast errors is essential. Without forecast errors, the central bank's forecasts could be verified ex-post and cheating by the central bank would be revealed. 


\section{Optimal interest rate without announcements}

The first-best solution is for the central bank to realize that it cannot systematically raise output above its natural level. It commits itself to setting a nominal interest rate on average equal to its inflation target (zero in this case). On top of that, the nominal interest rate responds to supply and demand shocks, so as to (partly) stabilize output. Optimizing the central bank's utility under the constraints of aggregate supply to equal aggregate demand yields the following first-best nominal rate of interest.

$$
i_{t}^{F B}=\frac{v_{t}}{b}-\frac{e_{t} f}{b\left(\theta^{2}+f\right)}
$$

\section{Figure 1 Sequence of events in first-best case}

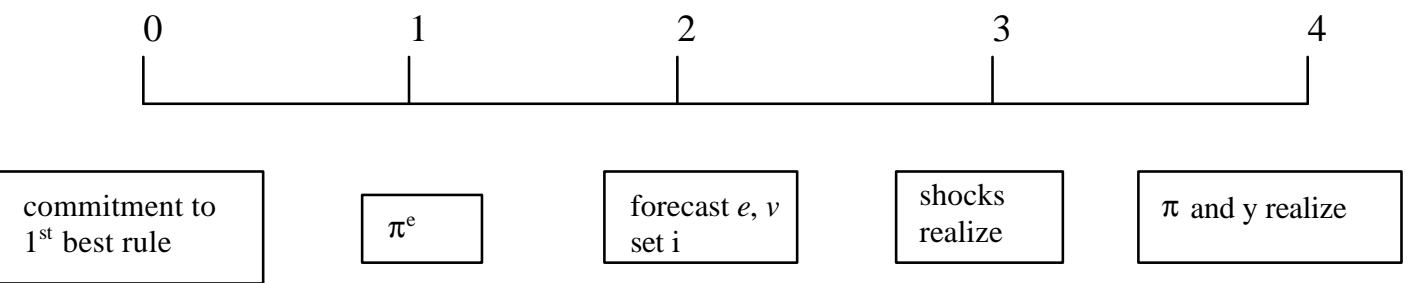

The public expects the central bank to implement the first-best interest-rate policy. Since the public's unconditional expectation of the central bank's private forecast equals zero (and the inflation target is zero, as well), it expects a nominal interest rate equal to zero and therefore an inflation rate equal to zero.

$$
\pi_{t}^{e}=0
$$

\section{Cheating}

Once the public has formed these expectations, the central bank will maximize its utility by setting the following nominal interest rate.

$$
i_{t}^{C H}=i_{t}^{F B}-\frac{\theta^{2} y^{*}}{b\left(\theta^{2}+f\right)}
$$


Due to the bank's ambitious output target $\left(y^{*}>0\right)$, it will set an interest rate that is lower than the first-best solution. In this way, it will stimulate aggregate demand because of the lower real interest rate. The output gap $\left(y_{t}\right)$ increases and the average rate of inflation will be positive. A conservative central bank (high $f$ ) will put a higher weight on the cost of higher inflation and will be less inclined to cheat.

Of course, this policy is not sustainable. The public will recognize the policy maker's incentive to cheat and set its inflationary expectations accordingly.

\section{Myopic}

The public will set its expected rate of inflation in such a way that the central bank has no incentive to surprise anymore, because the cost of additional inflation outweigh the benefit from additional output. The expected rate of inflation will be:

$$
\pi^{e}=\frac{\theta y^{*}}{f}
$$

Taking this expectation as given, the policymaker maximizes its utility by setting the following nominal interest rate

$$
i_{t}^{M Y}=i_{t}^{F B}+\frac{\theta y^{*}}{f}
$$

The central bank will accommodate the inflationary expectations by setting a higher nominal interest rate. The expected and realized real rate of interest will be the same as in the first-best solution and, apart from the higher inflation rate, all outcomes will be the same. This solution suffers from an inflationary bias. This is, however, fully anticipated by the public and therefore has no effect on the level of output.

\section{Precise announcements - not credible}

The central bank could decide to share its private information with the public. By making a precise, truthful announcement of the inflation rate that is to be expected, the central bank 
loses completely the its ability to stabilize supply shocks. This follows directly from the Lucas aggregate supply function (2). The nominal interest rates varies to keep the output gap equal to the supply shock and both inflation and expected inflation are always equal to zero.

However, as soon as the announcement is made and the inflationary expectations are fixed, the central bank will try to improve on this outcome and set a different nominal interest rate, implementing the cheating solution and making its announcement false.

\section{Imprecise anno uncement}

As we have seen, a rule that depends on the central bank's private forecast of supply and demand shocks does not work. Alternatively, monetary policy could consist of a fixed interest rate rule, in which the central bank's private forecast of supply and demand shocks plays no role.

Figure 2 Sequence of events with fixed nominal interest rate

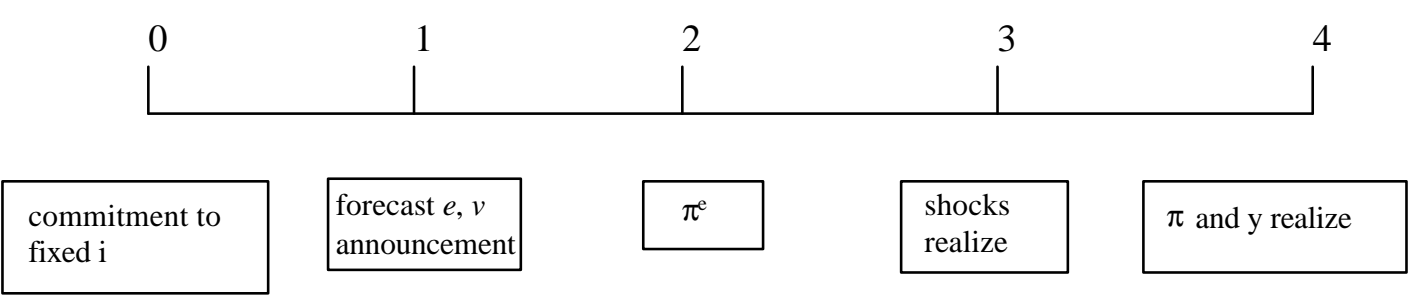

Optimally, with a zero inflation target, the nominal interest rate should be equal to zero.

$i_{t}^{\text {FIXED }}=0$

Setting this nominal interest rate would eliminate the inflationary bias, but allows no flexibility to react to demand and supply shocks. By giving up the flexibility to react to shocks, the policy maker gains credibility to eliminate the inflationary bias.

As is shown above, a precise announcement of the central bank's private information is not possible because the bank has an incentive to implement the cheating solution. However, it may be possible to make an imprecise announcement of the private information. By choosing the cut-off point in such a way that the central bank always derives at least as much utility from telling the truth as from lying, the bank can credibly announce the range in which its private forecast falls. 
Imposing the zero nominal interest rate and the condition that the central bank tells the truth, the rationally expected rate of inflation is $\pi_{t}^{e}=E\left[\frac{e_{t}-v_{t}}{b}\right]$.

As was argued before, a precise announcement of the rate of inflation that is to be expected is impossible. Alternatively, following Garfinkel and Oh (1995), the central bank could announce a range in which its privately expected inflation falls. More specifically, the announcement that the central bank makes, is whether the public should expect a rate of inflation higher or lower than cut-off point $X$.

$\pi_{t}^{e}=E\left[\frac{e_{t}-v_{t}}{b}\right]<>X$

To simplify the further analysis, we assume for the remainder of the paper that both the supply shock $e$ and the demand shock $v$ are independent and uniformly distributed.

$e_{t} \sim U[-A, A]$

$v_{t} \sim U[-C, C]$

Furthermore, to facilitate the computation of the expectations, we assume that the variance of demand shocks is larger than the variance of the supply shocks

$$
C \geq A+b|X|
$$

If the central bank announces the high-inflation range, the public expects:

$$
\pi_{H}^{e}=\frac{C+b X}{2 b}
$$

If the central bank announces the low-inflation range, the public expects:

$$
\pi_{L}^{e}=\frac{-C+b X}{2 b}
$$

\section{Central bank incentives}

The central bank will announce the high-inflation or the low-inflation range, depending on which announcement maximizes the central bank's utility. If we compare the central bank's 
utility with high and low public inflationary expectations, we find that the central bank is indifferent between the two announcements if

$$
v_{t}=\frac{2 b \theta^{2} y^{*}-\left(b^{2} \theta^{2}+f(b+\theta)^{2}\right) X+2 f(b+\theta) e_{t}}{2\left(f \theta+b\left(f+\theta^{2}\right)\right)}
$$

For larger $v$, the central bank prefers the lower inflation expectations and announces the low range, for smaller $v$ it prefers the higher and announces the high range.

Now, the public (that is fully aware of the central bank's incentives) should choose $X$ in such a way that the expected rate of inflation in the range that the central bank announced, coincides with the publics inflationary expectations.

$$
X=\frac{2 b \theta^{2} y^{*}}{f \theta^{2}-b^{2}\left(f+\theta^{2}\right)}
$$

This means that the central bank will be indifferent between announcing the high and the low range if

$$
v_{t}=\frac{2 b^{2} \theta^{2} y^{*}}{b^{2}\left(f+\theta^{2}\right)-f \theta^{2}}+\frac{f(b+\theta) e_{t}}{f \theta+b\left(f+\theta^{2}\right)}
$$

or

$$
e_{t}=\left(1+\frac{b \theta^{2}}{f(b+\theta)}\right)\left(X b+v_{t}\right)
$$

For larger $v$ (smaller $e$ ) it will announce low inflation and for smaller $v$ (larger $e$ ) it will announce high inflation. If low inflation is announced, the public will expect

$$
\pi_{L}^{e}=\frac{b \theta^{2} y^{*}}{b^{2}\left(f+\theta^{2}\right)-f \theta^{2}}-\frac{C}{2 b}
$$

For the high range, it expects

$$
\pi_{H}^{e}=\frac{b \theta^{2} y^{*}}{b^{2}\left(f+\theta^{2}\right)-f \theta^{2}}+\frac{C}{2 b}
$$




\section{Figure 3 Incentives for $\mathrm{X}<0$}

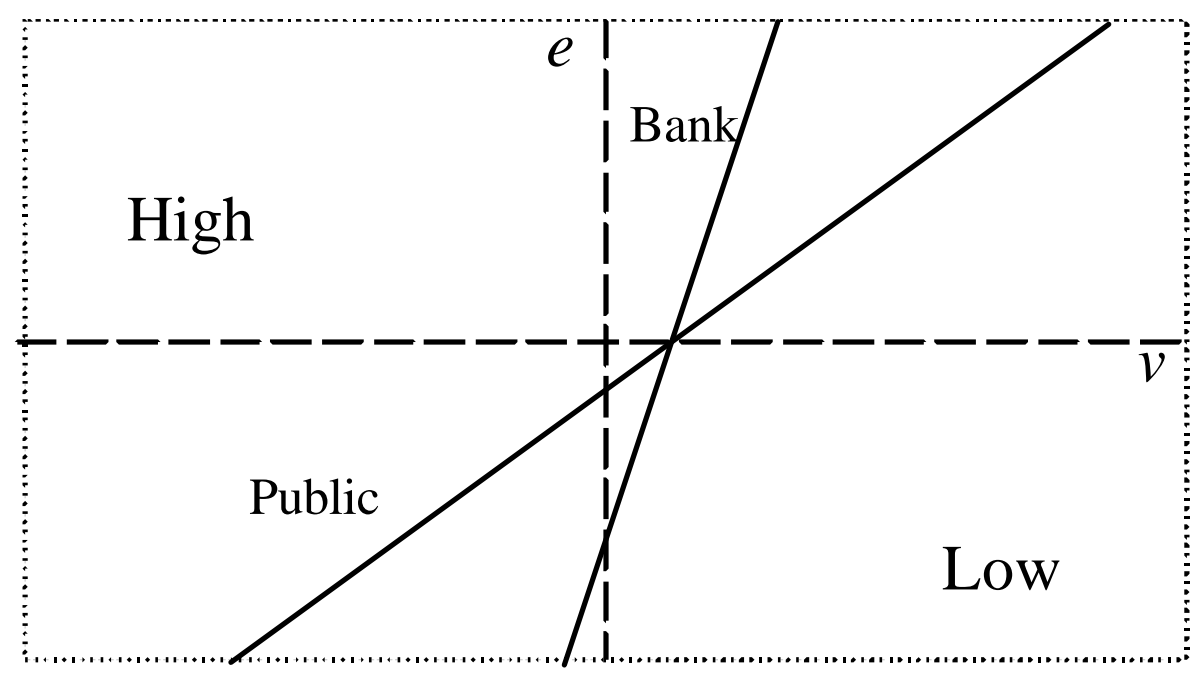

Interestingly, as Figure 3 shows, there is a region of supply and demand shocks in which the central bank's announcement is not a truthful representation of the bank's private information.

The public's indifference curve is a $45^{\circ}$-line that represents the combinations of aggregate supply and aggregate demand shocks where the public's expected rate of inflation $X$ exactly equals the realized rate of inflation (see equation (7)). For points to the left of this line, the public expects high inflation (9) and for points to the right of this line, the public expects low inflation (10).

The central bank's indifference curve is steeper than the public's, indicating that the central bank reacts more to demand shocks than to supply shocks. The slope of this line depends positively on $\theta$ (the effect of inflation surprises on the level of output) and negatively on $f$ (the central bank's relative weight on inflation stabilization). As a consequence of the different slope, there is an area between the two indifference curves where the central bank 'fools' the public. For positive values of supply shock $e$, the central bank is more inclined to announce the low-inflation region and for negative values of supply shock $e$, the central bank is more inclined to announce the high-inflation region, compared to the public. Since the area where the central bank overstates the rate of inflation is exactly as big as the area where the central bank understates the rate of inflation, the central bank's statements are correct on average. 
This discrepancy between the central bank's announcement and the public's expectation stems purely from the desire to stabilize output and is not related to the ambitious output target. The ambitious output target is, however, responsible for the location of border between the high and low inflation announcement. A value for $X>0$ indicates that having a low rate of inflation is more important to the central bank than stimulating output so that, in absence of any shock, the central bank will announce low inflation. Conversely, a value for $X<0$ indicates that the central bank finds stimulating output more important than having a low rate of inflation and that, in the absence of any shock, it will announce a high rate of inflation.

\section{Announcing interest rates}

Central bank announcements about the expected rate of inflation are not credible if the central bank sets interest rates as well. However, it is possible for the central bank to credibly announce both the range in which its inflation forecast falls and the nominal interest rate that it sets.

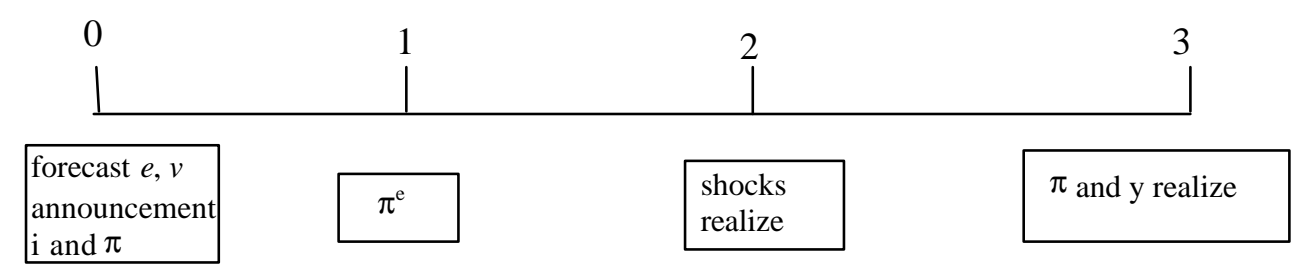

After the announcement by the central bank, the public sets its inflationary expectations taking the central bank's inflation and interest rate announcement into account:

$$
\begin{aligned}
& \pi_{L}^{e}=\frac{-C+b X}{2 b}+i_{L} \\
& \pi_{H}^{e}=\frac{C+b X}{2 b}+i_{H}
\end{aligned}
$$

After realization of the aggregate demand and supply shock, realized inflation will be:

$$
\pi_{L}=\left(\frac{1}{\theta}+\frac{1}{b}\right) \frac{X b-C}{2}+\frac{v-e}{\theta}+i_{L}
$$


$\pi_{H}=\left(\frac{1}{\theta}+\frac{1}{b}\right) \frac{X b+C}{2}+\frac{v-e}{\theta}+i_{H}$

And realized output will be

$y_{L}=\frac{X b-C}{2}+v$

$y_{H}=\frac{X b+C}{2}+v$

We solve this game backwards, starting by the central bank's decision to announce either high or low inflation (with the appropriate interest rate). The central bank is indifferent between announcing "High" or "Low" if

$v_{t}=\frac{2 b C \theta^{2} y^{*}-\left(b^{2} \theta^{2} C+f C(b+\theta)^{2}-b f \theta(\theta+b)\left(i_{L}-i_{H}\right)\right) X+2 f\left((b+\theta) C-b \theta\left(i_{L}-i_{H}\right)\right) e_{t}}{2\left(C f \theta+b C\left(f+\theta^{2}\right)-b f\left(i_{L}-i_{H}\right)\right)}$

Given this decision rule, the public determines the value of $X$ for which the expectations are consistent with the announcement (average inflation in the "High" area equals expected inflation in the "High" area and v.v.):

$$
X=\frac{\theta\left(-f\left(i_{H}+i_{L}\right)\left(C \theta+b\left(C+\theta\left(i_{H}-i_{L}\right)\right)\right)+2 b C \theta y^{*}\right)}{C f \theta^{2}+b f \theta^{2}\left(i_{H}-i_{L}\right)-b^{2}\left(f \theta\left(i_{H}-i_{L}\right)+C\left(f+\theta^{2}\right)\right)}
$$

Using (17) and taking (18) as given, the central bank will set $i_{H}$ and announce high inflation if

$e_{t}>\left(1+\frac{b C \theta^{2}}{f\left(C(b+\theta)-b \theta\left(i_{L}-i_{H}\right)\right)}\right)\left(X b+v_{t}\right)$

Compared to the case where just the range of inflation was announced, without an interest rate attached to the announcement, the central bank's announcement depends stronger on the realization of demand shock $v$. The reason for this effect is that the interest rate announcement greatly reduces the variance of inflation. Therefore, the policymaker can pay more attention to stabilizing demand shocks. 
Finally, the central bank chooses the optimal interest rates $i_{H}$ and $i_{L}$.

By adding-up the two first-order conditions, we find that it is optimal for the Central Bank to set:

$i_{L}+i_{H}=-\left(\frac{b}{\theta}+1\right) X$

or, alternatively by using (18) and (20)

$i_{H}=\frac{-2 C f \theta-b C\left(2 f+\theta^{2}\right)+\sqrt{\left(2 b C f+2 f \theta\left(C-2 b i_{L}\right)+b C \theta^{2}\right)^{2}+16 b C f \theta^{2}(b+\theta) y^{*}}}{4 b f \theta}\left(\mathbf{2 0}^{\prime}\right)$

For the second first-order condition of the central bank, we need a first-order Taylorexpansion. By substituting (20') in the Central Bank's first-order condition with respect to $i_{H}$ and expanding around $\left(y^{*}, i_{L}\right)=\left(0, \frac{c}{2 b}\right)$ we find the following approximation of optimal interest-rate setting by the central bank.

$i_{L}=\frac{C}{2 b}-\frac{A^{2} f \theta C}{4 A^{2} f \theta^{2}+9 C^{2}\left(f+\theta^{2}\right)^{2}}+\frac{\theta(b+\theta) y^{*}}{b\left(2 f+\theta^{2}\right)}$

Taking $i_{L}$ as given, a first-order Taylor expansion around $y^{*}=0$ gives the following expressions for $i_{H}$ and $X$ :

$i_{H}=-\frac{C}{2 b}+\frac{A^{2} f \theta C}{4 A^{2} f \theta^{2}+9 C^{2}\left(f+\theta^{2}\right)^{2}}+\frac{\theta(b+\theta) y^{*}}{b\left(2 f+\theta^{2}\right)} \cdot\left(1-\frac{8 A^{2} f^{2} \theta^{2}}{9 C^{2}\left(f+\theta^{2}\right)^{2}\left(2 f+\theta^{2}\right)+4 A^{2} f \theta^{2}\left(3 f+\theta^{2}\right)}\right)$

$X=-\frac{2 \theta^{2}\left(9 C^{2}\left(f+\theta^{2}\right)^{2}+4 A^{2} f \theta^{2}\right)}{b\left(9 C^{2}\left(f+\theta^{2}\right)^{2}\left(2 f+\theta^{2}\right)+4 A^{2} f \theta^{2}\left(3 f+\theta^{2}\right)\right)} y^{*}$

This solution significantly reduces the variance of inflation compared to the regime where the nominal interest rate is fixed and the central bank announces high or low inflation. 


\section{Welfare analysis}

We have presented three feasible monetary policy regimes: a myopic one, that suffers from an inflationary bias but is flexible in its reaction to shocks, one with a fixed nominal interest rate, that yields the optimal average rate of inflation, but gives no flexibility to react to shocks, and finally the regime in which the central bank makes a credible but imprecise announcement about the rate of inflation that is to be expected. In general, the myopic regime is optimal if the central bank's incentive to cheat is relatively small, that is if the output target is not too ambitious so $y^{*}$ is close to zero. On the other hand, the fixed nominal interest rate regime without an announcement is optimal is the variance of aggregate supply and aggregate demand shocks is relatively small, that is $A$ and $C$ are small. The intermediate regime with interest rate announcement is optimal in cases where $y^{*}$ is large, $f$ small and $C$ relatively large. In that set-up, the credibility problem is important, which makes the myopic regime unattractive. At the same time, demand shocks are relatively large so that a zero-inflation rule leads to large losses. In the following table, we give a numerical example where these conditions are met.

\section{Numerical example where imprecise announcement is optimal}

$A=0.1 ; C=0.2 ; b=1 ; f=0.1 ; \theta=1 ; y^{*}=0.05$

In this setting, the faces a serious credibility problem (an ambitious output target $y^{*}$ and low conservatism $f$ ) and aggregate demand shocks have a large variance $(C)$. In the optimal imprecise announcement regime, the central bank would set a nominal interest rate of 0.183 in the low-inflation range, yielding an average inflation rate of 0.041 and a nominal interest rate of -0.016 in the high-inflation range, resulting in an average inflation rate of 0.042 . 


\begin{tabular}{|l|l|l|l|}
\hline & Myopic & Interest Rate Rule & Optimal Announcement \\
\hline Expected inflation & 0.500 & 0 & 0.0418 \\
\hline Variance inflation & 0.00275 & 0.01667 & 0.0081 \\
\hline Variance output & 0.00003 & 0.01333 & 0.00508 \\
\hline Expected Loss & 0.0139 & 0.00875 & 0.00428 \\
\hline
\end{tabular}

\section{Concluding remarks}

In this paper, we explore a monetary policy game between the central bank and the public. The monetary authority possesses a private, non-verifiable forecast about aggregate supply and aggregate demand shocks. Due to the central bank's credibility problem, it cannot credibly announce its precise forecast. However, it can credibly announce a range in which its forecast falls. In contrast to Garfinkel and Oh (1995), we find that it is not possible to design an arrangement in which the central bank always truthfully reveals its private information. Even in the optimal arrangement, a range of supply and demand shocks exists for which the central bank makes an announcement that differs from what the public would choose. By doing this, the central bank tries to stabilize aggregate demand shocks. The central bank's desire to stabilize output, gives an incentive to announce low inflation in the event of a positive demand shock and high inflation in the event of a negative demand shock and therefore the central bank pays less attention to supply shocks than the public.

An arrangement as described in this paper, in which the central bank announces a range for its inflation forecast and an accompanying interest rate, can be attractive for policymakers that have low credibility (which makes the myopic solution costly) and at the same time face large demand shocks (which makes an inflation rule costly). The regime can be refined by defining more than just two ranges (see Crawford and Sobel (1982)) which enables the policymaker to transmit more precise information. 


\section{References}

Barro, R. and D. Gordon (1983), "A positive theory of monetary policy in a natural rate model”, Journal of Political Economy, 91, pp. 589-610.

Canzoneri, M. (1985), "Monetary policy games and the role of private information", American Economic Review, 75, pp. 1056-1070.

Crawford, V. and J. Sobel (1982), "Strategic information transmission", Econometrica, 50, pp.1431-1451.

Cukierman, A. and A. Meltzer (1986), “A theory of ambiguity, credibility, and inflation under discretion and asymmetric information", Econometrica, 54, pp. 1099-1128.

Garfinkel, M. and S. Oh (1995), "When and how much to talk: Credibility and flexibility in monetary policy with private information", Journal of Monetary Economics, 35, pp. 341-357.

Geraats, P. (2001), "Why adopt transparency? The publication of central bank forecasts", European Central Bank Working Paper Series, No. 41, January.

Kydland, F. and E. Prescott (1977), "Rules rather than discretion: The inconsistency of optimal plans", Journal of Political Economy, 85, pp. 473-491.

Peek, J., E. Rosengren and G. Tootell (1999), “Using Bank Supervisory Data Improve Macroeconomic Forecasts", New England Economic Review, September/October, pp.21-32.

Romer, C. and D. Romer (2000), "Federal Reserve Private Information and the Behavior of Interest Rates", American Economic Review, 90, pp. 429-457.

Stein, J. (1989), "Cheap talk and the Fed: A theory of imprecise policy announcements", American Economic Review, 79, pp. 32-42.

Yetman, J. (2002), 'Publishing Central Bank Forecasts", mimeo University of Hong Kong. 